\title{
Functionalized polystyrene beads as carriers in release studies of two herbicides: 2,4-dichlorophenoxyacetic acid and 2-methyl-4-chlorophenoxyacetic acid
}

\author{
A. Olejnik ${ }^{1}$ (I. I. Nowak ${ }^{1} \cdot$ G. Schroeder ${ }^{1}$
}

Received: 1 August 2017 / Revised: 20 November 2018 / Accepted: 26 November 2018 / Published online: 1 December 2018

(c) The Author(s) 2018

\begin{abstract}
The extensive usage of pesticides in agriculture has adverse effect on the quality of water and soil; therefore, the proper dosage is of great concern. The aim of this study was to use the functionalized polystyrene beads (QuadraPure ${ }^{\mathrm{TM}}$ ) as a reservoir for the storage and controlled release of two herbicides: 2,4-dichlorophenoxyacetic acid and 2-methyl-4-chlorophenoxyacetic acid. It was proved that desorption of herbicides was strongly affected by the surface properties of polystyrene beads characterized by different pore size distributions and modified with various functional groups. We suggest that the optimal hybrid systems are the mixtures that are able to release the high amount of herbicides for a long time. For 2,4-dichlorophenoxyacetic acid, these conditions were fulfilled by polystyrene beads with the attached imino diacetate or thiourea functional groups. For 2-methyl-4-chlorophenoxyacetic acid, the appropriate results were obtained when polystyrene beads with the thiourea functional groups were applied. Additionally, QuadraPure ${ }^{\mathrm{TM}}$ scavengers could form stable complexes with copper and nickel ions, and therefore, the pesticide release was limited. The application of a hybrid system permitted to control the distribution of the herbicide by the formation of complexes between metal ions and organic groups of QuadraPure ${ }^{\mathrm{TM}}$ materials. The results proved that by using the polystyrene beads the release of herbicide could be controlled.
\end{abstract}

Editorial responsibility: M. Abbaspour.

A. Olejnik

annamar@amu.edu.pl

1 Faculty of Chemistry, Adam Mickiewicz University

in Poznań, Umultowska 89b, 61-614 Poznan, Poland 


\section{Graphical abstract}

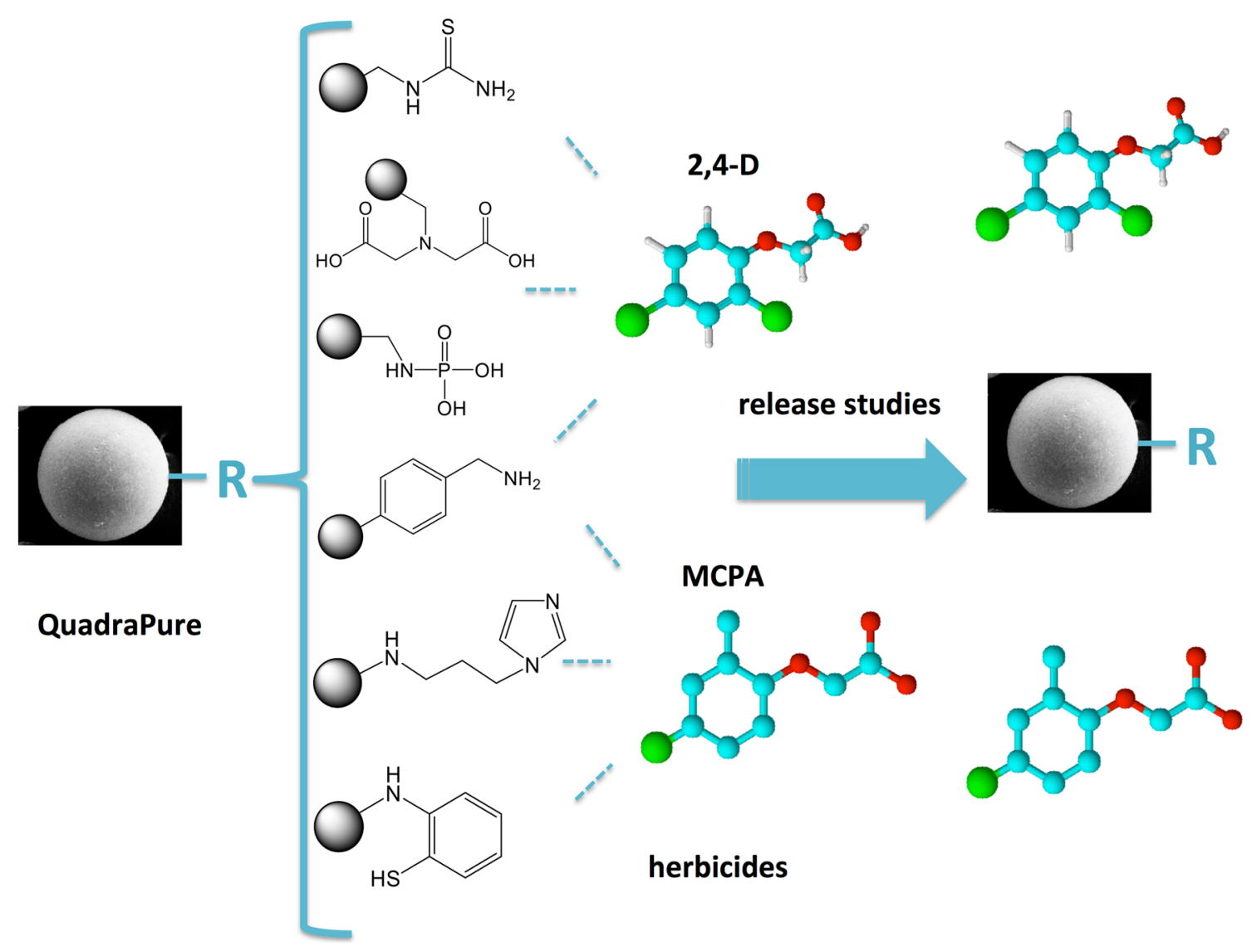

Keywords Hybrid system $\cdot$ Metal ion complexes $\cdot$ Pesticides $\cdot$ Release kinetics $\cdot$ Scavengers

\section{Introduction}

Pesticides are commonly applied in agriculture to destroy and repel weeds, pests and other microorganisms. However, they can be harmful to animals, humans and the environment (Stoytcheva 2011). The extensive usage of pesticides in agriculture has adverse influence on the quality of water and soil. Therefore, it is important to control the dosage of pesticides used. 2,4-Dichlorophenoxyacetic acid (2,4D) (Fig. 1a) is one of the most extensively applied herbicides in commercially available products because of its cost-effectiveness and high selectivity (Boivin et al. 2005; Trivedi et al. 2016). This compound can be found in mixtures of agricultural herbicides that are often used in the land of growing wheat and corn, in pastureland, lawns and turf where it effectively controls invasive and unwanted weeds (Howard 1991; Abigail and Chidambaram 2016). This pesticide has often been detected in groundwater supplies in Europe and North America (Gold et al. 1988). There are over 1500 herbicide and pesticide products on the market that contain 2,4-D as the main component (Howard 1991; Aylward and Hays 2008). However, the acid form is poorly soluble, and therefore, some herbicide formulations consist of more soluble forms such as their sodium salts (soluble in water), ammonium salts or esters (soluble in oils). The plant roots can absorb the salt forms of 2,4-D, while the ester forms penetrate foliage (Vencill 2002).

Furthermore, the ester forms are converted to the acid within the plant. Then accumulation in cells occurs due to passive diffusion down the concentration gradient. The acid form is responsible for uncontrolled cell division in vascular tissues that can cause the death of plants. Another example of a widely used herbicide is 2-methyl-4-chlorophenoxyacetic acid (MCPA, Fig. 1b). Both 2,4-D and MCPA belong to the class of compounds known as phenoxyalkanoic acids. MCPA is used to control broadleaf weeds in agricultural applications, especially in the production of cereals (barley, oats, rye, wheat), grasses, cotton, field crops and turf (Lin et al. 2013; Yang et al. 2016). MCPA is absorbed through leaves and roots. Furthermore, this herbicide is 
Fig. 1 Chemical structure of 2,4-dichlorophenoxyacetic acid (a) and 2-methyl-4-chlorophenoxyacetic acid (b)
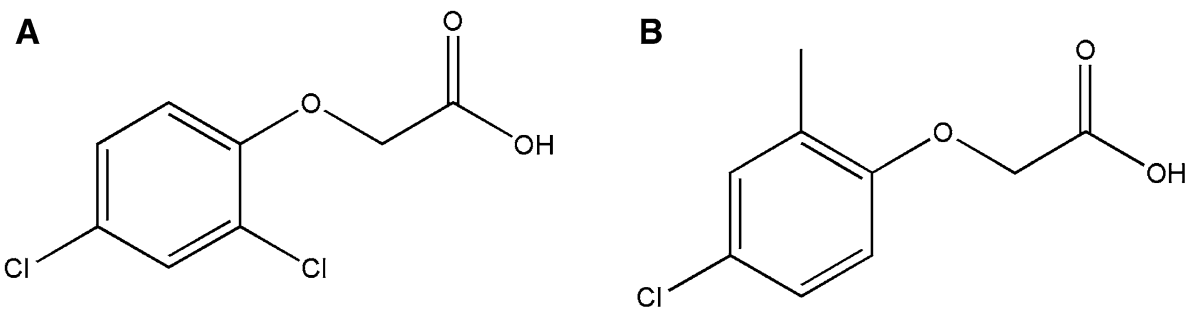

easily translocated throughout the plants and influences the synthesis of nucleic acid and protein that affect the activity of enzymes, respiration and cell division. MCPA is released directly to the environment after its applications. In order to control the acute toxicity of pesticides, new forms of MCPA and 2,4-D, known as herbicidal ionic liquids, have been recently synthesized. Novel generation of herbicides in the form of ammonium salts containing herbicidal anions2,4-D or MCPA - exhibited higher biological activity and better efficacy than the other pesticide salts (Pernak et al. 2011, 2012, 2013; Praczyk et al. 2012). The biological activity of herbicides depends to a large extent on their concentration and exposure time. Recently, nanostructured liquid crystalline particles have been applied as delivery vehicle for 2,4-D (Nadiminti et al. 2016). Herein, we propose a method for obtaining hybrid materials consisting of QuadraPure ${ }^{\mathrm{TM}}$ polymer-based spherical scavengers and the herbicide (2,4-D or MCPA). We suggest that the efficiency of products containing herbicides can be increased by slow release of the active compound from hybrid systems. QuadraPure ${ }^{\mathrm{TM}}$ scavengers are functionalized microporous or macroporous polystyrene-based resin beads. They are applied to remove or recover the precious metal contamination from products (Richardson and Jones 2006; Nikbin et al. 2007; Liew et al. 2014). Polystyrene beads have also been used as carriers of liquid biocides, added before copolymerization, for their controlled release (Iconomopoulou et al. 2005). In this work, the functionalized polystyrene beads (QuadraPure ${ }^{\mathrm{TM}}$ ) were used for the first time as a reservoir for the storage and controlled release of 2,4-D and MCPA. The role of the scavengers' terminal functional groups in forming bonds with the herbicide is discussed. Furthermore, the release kinetics of 2,4-D and MCPA from the hybrid system is presented. This study was conducted at the Faculty of Chemistry of Adam Mickiewicz University in Poznań from 2012 to 2016.

\section{Materials and methods}

\section{Chemicals}

2,4-D and MCPA were purchased from Sigma-Aldrich. Ethanol (95\%) was obtained from POCH S.A. (Gliwice,
Poland), and potassium phosphate buffer was purchased from J.T. Baker (Phillipsburg, NJ, USA). Copper and nickel salts of 2,4-D and MCPA were prepared by using coper(II) or nickel(II) carbonate (Utschick et al. 1989). The salts of tetra- $n$-butylammonium 2,4-D and MCPA were synthesized by using tetra- $n$-butylammonium hydroxide as a substrate (Sigma-Aldrich). The formation of 2,4-D and MCPA salts was confirmed by ESI mass spectrometry studies (Waters/ Micromass ZQ mass spectrometer, Manchester, UK).

Two ranges of QuadraPure ${ }^{\mathrm{TM}}$ macroporous and microporous scavengers (Sigma-Aldrich) were applied to form hybrid systems with the herbicides. The chemical structure of QuadraPure ${ }^{\mathrm{TM}}$ and its characterization are summarized in Table 1.

\section{Sample preparation - formation of hybrid system}

A portion of $5 \mathrm{mg}$ of 2,4-D or MCPA was dissolved in $5 \mathrm{ml}$ of ethanol. Next, the selected QuadraPure ${ }^{\mathrm{TM}}$ material $(100 \mathrm{mg})$ was added to the herbicide solution. The mixture was left in a drying oven at $35^{\circ} \mathrm{C}$ for $24 \mathrm{~h}$. After evaporation of ethanol, a hybrid system was obtained which was then used to control the release of 2,4-D and MCPA. The same preparation procedure was performed for herbicide salts such as $\mathrm{Cu}(2,4-\mathrm{D} \text { anion })_{2}, \mathrm{Ni}(2,4-\mathrm{D} \text { anion })_{2}, \mathrm{R}_{4} \mathrm{~N}(2,4-\mathrm{D}$ anion $)$, $\mathrm{Cu}(\mathrm{MCPA} \text { anion })_{2}, \mathrm{Ni}(\mathrm{MCPA} \text { anion })_{2}$, and $\mathrm{R}_{4} \mathrm{~N}(\mathrm{MCPA}$ anion).

\section{In vitro release test}

In vitro release studies were performed with the USP Dissolution Apparatus 2 (Varian Vankel 7010) connected with a UV-Vis spectrophotometer (Cary 50 Bio, Varian, USA). The hybrid system containing selected QuadraPure TM material and herbicide (or their salts) was placed in the Enhancer cell (also known as the Vertical Diffusion Cell or External Receptor Chamber Type) made of PTFE. In order to maintain appropriate experimental conditions, the hybrid system was sandwiched between porous synthetic nets. Potassium phosphate buffer at $\mathrm{pH} 6.8$ was used as the receiving medium to reflect the neutral $\mathrm{pH}$ condition. The medium $(200 \mathrm{ml})$ was maintained at $25.0{ }^{\circ} \mathrm{C} \pm 0.5^{\circ} \mathrm{C}$ and stirred at $100 \mathrm{rpm}$. During the measurement, the samples 
Table 1 QuadraPure ${ }^{\mathrm{TM}}$ structure and characterization

\begin{tabular}{ll}
\hline QuadraPure ${ }^{\mathrm{TM}}$ type & Description \\
Macroporous & \\
$\mathrm{TU}$ & Macroporous $\mu \mathrm{m}$ particle size \\
$350-750 \mu \mathrm{m}$ particle size & Macroporous \\
350-750 $\mu \mathrm{m}$ particle size & $\begin{array}{l}\text { Macroporous } \\
400-1100 \mu \mathrm{m} \text { particle size }\end{array}$ \\
AMPA & $\begin{array}{l}\text { Microporous } \\
100-400 \mu \mathrm{m} \text { particle size }\end{array}$ \\
IMDAZ & $\begin{array}{l}\text { Microporous } \\
100-400 \mu \mathrm{m} \text { particle size }\end{array}$
\end{tabular}

were collected at certain intervals and filtered through cannula filters (35- $\mu \mathrm{m}$ High-density Polyethylene Full Flow Filters). Next, the concentration of pesticide released was monitored at $283 \mathrm{~nm}$ for 2,4-D (and their salts) and $280 \mathrm{~nm}$ for MCPA (and their salts) over $18 \mathrm{~h}$. The measured absorbance was used to calculate the amount of herbicide released at each point in time of the analysis. In addition, the reference standard solutions for each herbicide and their salts were prepared in order to generate the standard curve of absorbance versus concentration. All release experiments for each sample were performed in triplicate, and results were represented as mean \pm standard deviation (SD).

\section{Release kinetics models}

Semiempirical mathematical models were used to describe the kinetics of herbicide release from QuadraPure ${ }^{\mathrm{TM}}$ macroporous and microporous scavengers. The kinetic models are applied to determine the release mechanism of the active compound. By comparing the release data with mathematical models, a physical mechanism of herbicide transport from polymers can be inferred. Its knowledge is useful and helpful to control the release of 2,4-D and MCPA from QuadraPure ${ }^{\mathrm{TM}}$ macroporous and microporous scavengers.
The release data were fitted with several kinetic models, including:

1. zero order (the graph is presented as $\%$ herbicide release vs. time),

$Q_{t}=Q_{0}+K_{0} t$

where $Q_{0}$-initial amount of herbicide, $Q_{t}$-amount of herbicide at time " $t$," $K_{0}$-zero-order release constant, $t$-time,

2. first order (the graph is presented as log of $\%$ herbicide remaining vs. time),

$\log Q_{t}=\log Q_{0}-K t / 2.303$

where $Q_{0}$-initial amount of herbicide, $Q_{t}$-amount of herbicide release at time " $t$," $K$-first-order release constant, $t$-time,

3. Higuchi model (the graph is presented as $\%$ herbicide release vs. square root of time)

$Q=K_{\mathrm{H}} t^{1 / 2}$

where $Q$-amount of herbicide release at time " $t$," $K_{\mathrm{H}}$ Higuchi constant, $t$ - time

and

4) Korsmeyer-Peppas model (the graph is plotted as log of $\%$ herbicide release vs. log time) 


$$
F=\left(M_{t} / M\right)=K t^{n}
$$

where $F$-fraction of herbicide released at time " $t$," $M_{t}$-amount of herbicide released at time " $t$," $M$-total amount of herbicide release at time " $t$," $K$-kinetic constant, $n$-release exponent, $t$-time (Dash et al. 2010; Goscianska et al. 2016; Lewandowski et al. 2014; Olejnik et al. 2017; Sahoo et al. 2012).

The release data were fitted to the most important kinetic models in order to understand and describe the mechanism of herbicide transport from QuadraPure ${ }^{\mathrm{TM}}$ materials. In zero-order kinetic model, the same amount of the active compound is released per unit time. The release rate of the substance is independent of its concentration. First-order kinetics is applied for matrix diffusion controlled release and sustained release. The active compound release rate depends on its concentration. Higuchi model is used to study the release of an active compound from solid and semisolid matrices (Salome et al. 2013). It describes the release of substance according to the diffusion process based on Fick's law (Ramteke et al. 2014). The Korsmeyer-Peppas model provides information about the release and transport of the active compound. This model was chosen in our study because it was often used to describe the release mechanism from polymeric systems of different geometries (Siepmann and Siepmann 2008). The $n$ value permits identification if the transport of a given substance follows the Fickian or non-Fickian diffusion or if it is so-called anomalous transport or polymer swelling. The $R^{2}$ values were calculated for each mathematical model. The higher the determination coefficient $\left(R^{2}\right)$, the more suitable a given kinetics model was. Additionally, the rate constant $(k)$ and the herbicide half-time release were obtained from the kinetic curves by using Guggenheim's method (Schwetlick 1971).

\section{Results and discussion}

As presented in Table 1, QuadraPure ${ }^{\mathrm{TM}}$ materials have different particle sizes and various functional groups attached to polystyrene such as thiourea (TU), imino diacetate (IDA), aminomethyl phosphonic acid (AMPA), benzyl amine (BZA), imidazol-1-yl propyl amino (IMDAZ), mercaptophenyl amino (MPA). These functional groups are responsible for the specific properties of the functionalized polystyrene beads. These materials possess amino or carboxyl functional groups which are able to form hydrogen bonds with the carboxylic groups of the herbicides (Fig. 2). Furthermore,

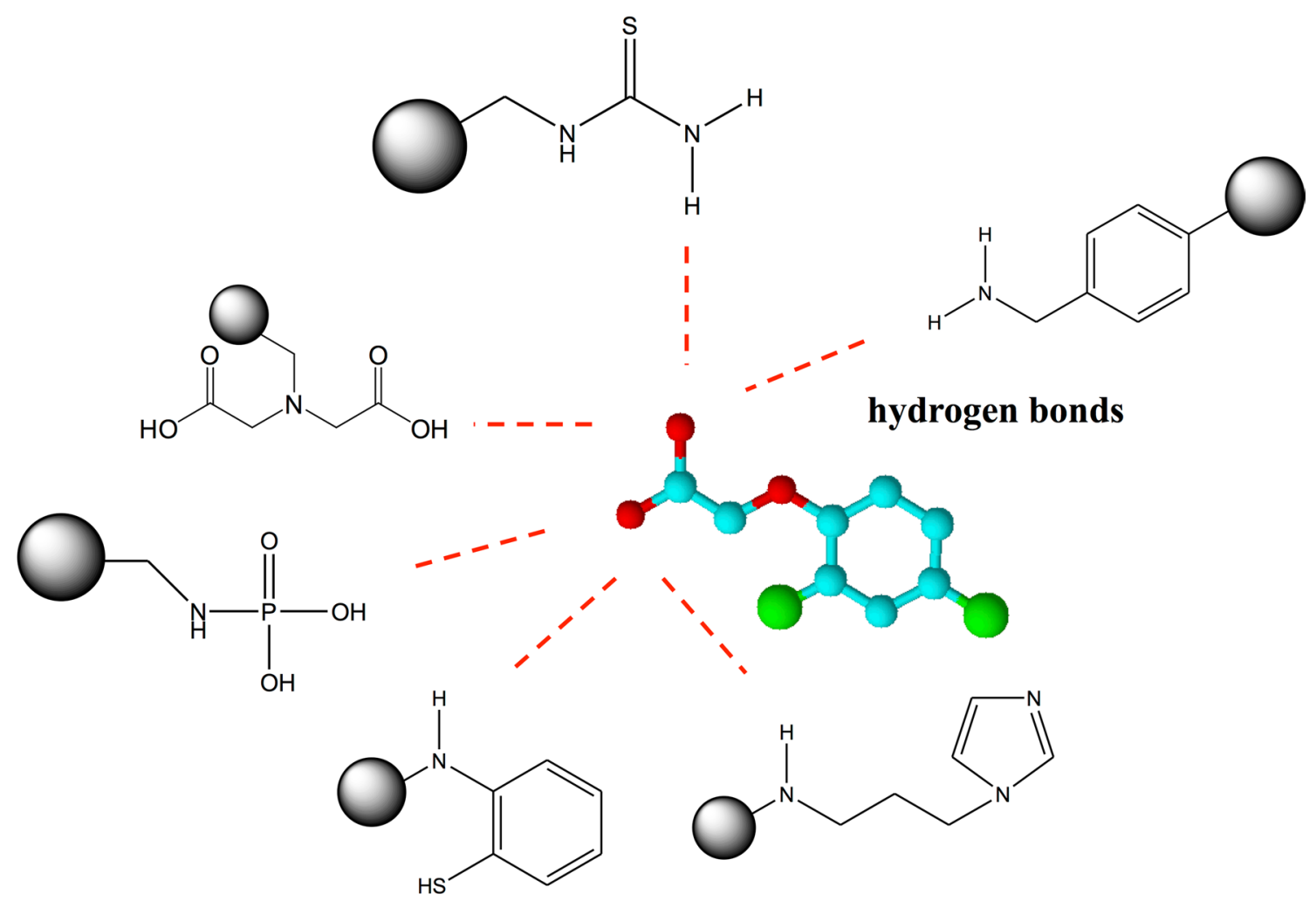

Fig. 2 Interactions between 2,4-D and various QuadraPure ${ }^{\mathrm{TM}}$ materials 
these hydrogen bonds can vary in strength. The strength of hydrogen bond is determined by electronegativity of the atoms that interact with each other (hydrogen atom and electronegative atoms such as $\mathrm{O}$ and $\mathrm{N}$ ) and the number of hydrogen bonds formed. According to strength, the hydrogen bonds are ordered as follows $\mathrm{O}-\mathrm{H} \cdot \cdots \mathrm{N}>\mathrm{O}-\mathrm{H} \cdots \cdot \mathrm{O}>\mathrm{N}-\mathrm{H} \cdot \cdot$ $\cdot \cdot \mathrm{N}>\mathrm{N}-\mathrm{H} \cdots \mathrm{O} \gg \mathrm{C}-\mathrm{H} \cdots \mathrm{O}$. The energy of hydrogen bonds comprises contributions of charge transfer energy, Coulomb attractions, polarization and charge transfer energies. The distance between atoms in hydrogen bonds is determined by the resultant of the attractive and repulsive forces. The shift of electron density (in the atoms forming a hydrogen bond) is not only related to the free electron pair (involved in the formation of hydrogen bond), but to the entire molecule. It should be added that while the hydrogen bond $(\mathrm{AH} \cdots \mathrm{B})$ is formed, a dipole moment is generated directed from $\mathrm{B}$ atom to the $\mathrm{AH}$ bond. The magnitude of the dipole moment increases with increasing acid-base properties of the molecules that interact with each other. The acetic acid derivatives 2,4-D ( $\mathrm{pKa}=3.31$ at $25^{\circ} \mathrm{C}$ in water) and MCPA (pKa $=3.11$ at $25^{\circ} \mathrm{C}$ in water) have similar acid-base properties. The hybrid system is formed as a result of the interactions between amine and carboxyl groups of QuadraPure ${ }^{\mathrm{TM}}$ materials and the herbicide. As hybrid materials are porous, one cannot exclude the impact of water molecules (localized in cavities/pores) on these interactions. The adjacent water may be essential to stabilize transition states in which the hydrogen-bonding network is significantly changed. Due to the formation of hydrogen bonds, the channels/cavities may reach high flexibility while preserving their energetic stability (Hildebrand et al. 2008).

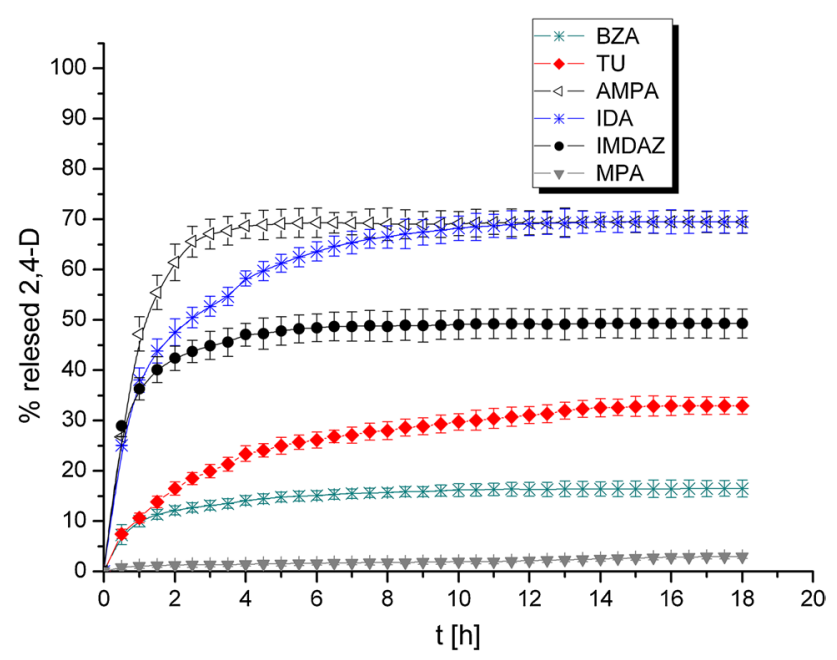

Fig. 3 Release profiles of 2,4-D from various QuadraPure ${ }^{\mathrm{TM}}$ in potassium phosphate buffer at $\mathrm{pH} 6.8$

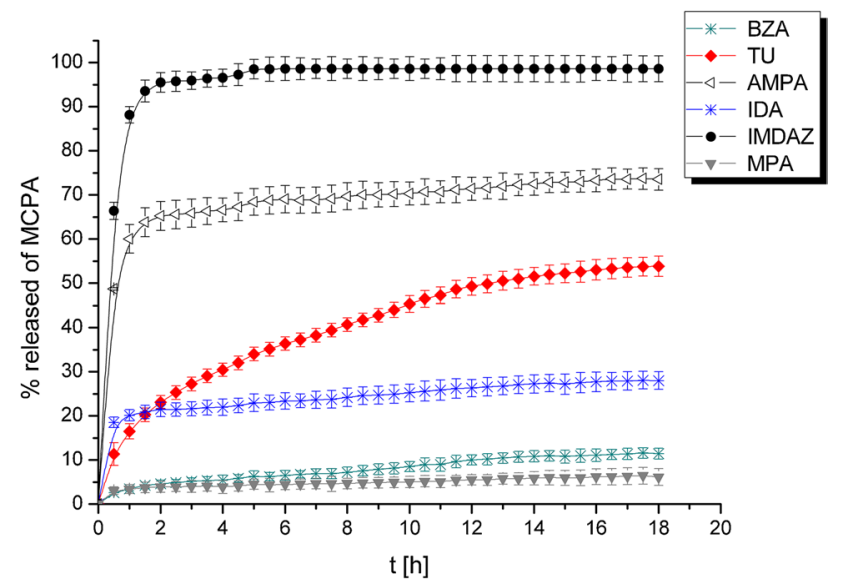

Fig. 4 Release profiles of MCPA from various QuadraPure ${ }^{\mathrm{TM}}$ in potassium phosphate buffer at $\mathrm{pH} 6.8$

\section{Release of 2,4-dichlorophenoxyacetic acid and 2-methyl-4-chlorophenoxyacetic acid from functionalized polystyrene beads}

After the formation of a hybrid system, the in vitro release studies of the herbicides were studied. Figures 3 and 4 present the amount of released herbicides from macroporous and microporous particles as a function of time. Table 2 shows the kinetic parameters, rate constants $(k)$ calculated using Guggenheim's method and half-release times $\left(t_{1 / 2}\right)$ of 2,4-D and MCPA from various QuadraPure materials. When the amount of herbicide released was very low, the halfrelease time was not determined. The obtained results indicated that after $18 \mathrm{~h}$ the amount of 2,4-D released from functionalized beads: AMPA, IDA, IMDAZ, TU, BZA and MPA reached $70 \%, 70 \%, 49 \%, 32 \%, 15 \%$ and $2 \%$, respectively. On the basis of the results, it was found that in the case of 2,4-D, the maximum amount (only 70\%) was released from AMPA and IDA, while $100 \%$ of MCPA was released from IMDAZ. It can be suggested that due to the presence of the long chain of imidazol-1-yl propyl amino groups attached to micropore openings of QuadraPure ${ }^{\mathrm{TM}}$, the molecules of the herbicide were gathered mainly on the external surface of this material. Therefore, the early burst release of MCPA from IMDAZ was observed.

Furthermore, the interactions (formation of hydrogen bonds, Fig. 2) between 2,4-D and the functional groups of BZA, TU and MPA were very strong, so less than $50 \%$ of the herbicide was released. A similar pattern was observed for MCPA, as less than $50 \%$ of the herbicide was released from BZA, IDA and MPA.

The lowest amount of both 2,4-D and MCPA was released from MPA. We assume that the mercaptophenyl 
Table 2 Kinetic parameters: rate constant $(k)$ and the herbicide half-time release $\left(t_{1 / 2}\right)$ for 2,4-D and MCPA herbicides

\begin{tabular}{|c|c|c|c|c|c|c|}
\hline QuadraPure $^{\mathrm{TM}}$ & BZA & TU & AMPA & IDA & IMDAZ & MPA \\
\hline \multicolumn{7}{|l|}{ 2,4-D herbicide } \\
\hline$k\left[\mathrm{~h}^{-1}\right]$ & 0.83 & 0.45 & 1.15 & 0.64 & 0.88 & 0.80 \\
\hline$t_{1 / 2}[\mathrm{~h}]$ & - & - & 1.10 & 2.50 & 20.00 & - \\
\hline \multicolumn{7}{|c|}{ MCPA herbicide } \\
\hline$k\left[\mathrm{~h}^{-1}\right]$ & 1.30 & 0.65 & 2.51 & 2.69 & 2.63 & 1.72 \\
\hline$t_{1 / 2}[\mathrm{~h}]$ & - & 13.00 & 0.50 & - & 0.35 & - \\
\hline
\end{tabular}

amino group was responsible for strong interactions with both herbicides. The hydrogen bonds were formed between the amine group of MPA and the carboxylic group of the herbicide. Additionally, the presence of thiol (-SH) might enhance the strength of interactions with the herbicide. Furthermore, also hydrophobic interactions between the aromatic rings of MCPA and the pesticide may occur. Therefore, the release process was not effective when compared to the other QuadraPure ${ }^{\mathrm{TM}}$ materials applied. Low amount of the herbicide was also released from BZA due to the presence of hydrogen bonds formed between the amine group of QuadraPure ${ }^{\mathrm{TM}}$ and the carboxylic group of the herbicide. Furthermore, we assumed that there were also hydrophobic interactions between the aromatic rings of MCPA and the pesticide. It should be mentioned that BZA belongs to the group of macroporous QuadraPure ${ }^{\mathrm{TM}}$ materials; therefore, the herbicide could be expected to be also loaded inside the macropores and because of that it could not be easily released to the receptor fluid.

The release rates of the examined molecules described by the release constant can be divided into two groups of systems. The first group of systems is characterized by high release constants $(>1)$, and the herbicide is released very fast. The second group comprises the systems characterized by the release constant $<1$, and the herbicide is released very slowly. The optimal hybrid systems should release high amount of herbicides for a long time. These conditions were fulfilled by TU and IDA (it was estimated that $50 \%$ of herbicide could be released after more than $100 \mathrm{~h}$ ) for 2,4-D and by TU for MCPA. The terminal groups of QuadraPure ${ }^{\mathrm{TM}}$ were responsible for forming strong hydrogen bonds with the carboxylic acid of herbicides. It has been reported that the neutral 2,4-D molecules were able to form stable complexes by hydrogen bonds in a polar solvent environment with a large variety of functional groups (for example, $-\mathrm{COOH}$, $-\mathrm{NH}_{2}$ ) (Aquino et al. 2007). Additionally, van der Waals forces were also responsible for the interactions between 2,4-D/MCPA molecules and the functional groups of QuadraPure ${ }^{\mathrm{TM}}$. However, van der Waals forces are relatively weak electric forces when compared to hydrogen bond interactions. The molecules of materials presented in this study, although electrically neutral, are permanent electric dipoles. In the presence of such molecules, the electric charge in the other polar or nonpolar molecules is disturbed, thus inducing further polarization. In the system formed, the additional attractive forces result from the interactions of permanent dipole with neighboring dipoles. Both van der Waals forces and hydrogen bonds act simultaneously and are responsible for interactions between the herbicide molecules and QuadraPure ${ }^{\mathrm{TM}}$ material. 2,4-D/MCPA molecules form complexes with functional group of selected functionalized polystyrene bead through hydrogen bonds. At the same time, also van der Waals forces contribute to intermolecular bonding between the herbicide and QuadraPure ${ }^{\mathrm{TM}}$ material.
Table 3 Kinetic models used to describe 2,4-D release from QuadraPure $^{\text {TM }}$ materials

\begin{tabular}{lllllll}
\hline Type of material & $\begin{array}{l}\text { Zero } \\
\text { kinetic } \\
\text { order }\end{array}$ & First kinetic order & Higuchi model & $\begin{array}{l}\text { Korsmeyer- } \\
\text { Peppas model }\end{array}$ & Type of transport \\
\cline { 5 - 6 } & Regression coefficient $\left(R^{2}\right)$ & & 0.962 & \\
\hline BZA & 0.871 & 0.878 & 0.945 & 0.966 & 0.302 & Fickian diffusion \\
TU & 0.974 & 0.982 & 0.997 & 0.998 & 0.553 & Non-Fickian diffusion \\
AMPA & 0.773 & 0.855 & 0.876 & 0.900 & 0.432 & Fickian diffusion \\
IDA & 0.888 & 0.937 & 0.955 & 0.962 & 0.380 & Fickian diffusion \\
IMDAZ & 0.849 & 0.877 & 0.931 & 0.966 & 0.224 & Fickian diffusion \\
MPA & 0.914 & 0.915 & 0.969 & 0.984 & 0.261 & Fickian diffusion \\
\hline
\end{tabular}


Table 4 Kinetic models used to describe MCPA release from QuadraPure $^{\mathrm{TM}}$ materials

\begin{tabular}{lllllll}
\hline Type of material & $\begin{array}{l}\text { Zero } \\
\text { kinetic } \\
\text { order }\end{array}$ & First kinetic order & Higuchi model & $\begin{array}{l}\text { Korsmeyer- } \\
\text { Peppas model }\end{array}$ & Type of transport \\
\cline { 5 - 6 } & Regression coefficient $\left(R^{2}\right)$ & & & & \\
\cline { 5 - 6 } & 0.894 & 0.896 & 0.962 & 0.979 & 0.354 & Fickian diffusion \\
BZA & 0.953 & 0.967 & 0.994 & 0.995 & 0.475 & Non-Fickian diffusion \\
TU & 0.845 & 0.874 & 0.909 & 0.946 & 0.216 & Fickian diffusion \\
AMPA & 0.774 & 0.778 & 0.873 & 0.944 & 0.079 & Fickian diffusion \\
IDA & 0.801 & 0.881 & 0.873 & 0.915 & 0.268 & Fickian diffusion \\
IMDAZ & 0.817 & 0.818 & 0.906 & 0.957 & 0.143 & Fickian diffusion \\
MPA & & & & & &
\end{tabular}

In Tables 3 and 4, the kinetic models that were used to describe the release of herbicides from QuadraPure ${ }^{\mathrm{TM}}$ materials are presented. The release results were fitted with four different mathematical equations and $\mathrm{R}^{2}$ that defines the approximation accuracy of each model was calculated. The highest values of correlation coefficient were obtained for the Korsmeyer-Peppas model ( $R^{2}$ ranged from $0.900-0.998$ for $2,4-\mathrm{D}$ and $0.915-0.995$ for MCPA). The higher the $R^{2}$, the more suitable a given kinetics model. Since the zero-order, first-order and Higuchi model curves did not fit sufficiently to the release results ( $R^{2}$-Tables 3 and 4 ), it could be suggested that the Korsmeyer-Peppas model best described the release of both herbicides from all functionalized polystyrene beads. Zero order was not suitable because in this model the same amount of active compound should be released in the unit time. The first-order model did not fit because the active compound should be released in a way that is proportional to the amount of compound remaining in its interior (Costa and Lobo 2001). Higuchi model was not appropriate because it is based on the hypothesis that the diffusion of the active compound is constant (Ramteke et al. 2014). However, the Korsmeyer-Peppas model was the best to be used in this study because it describes the release of herbicide from a polymeric system. Additionally, on the basis of the Korsmeyer-Peppas model it was possible to elucidate the mechanism of herbicide release from QuadraPure materials. The release exponent ( $n$ value) calculated on the basis of Korsmeyer-Peppas model characterizes the release mechanism of the active compound $(0.45 \leq n$ is related to a Fickian diffusion, $0.45<n<0.89$ corresponds to non-Fickian transport, $n-$ 0.89 is related to Case II transport, $n>0.89$ corresponds to super case II transport) (Riger and Peppas 1987; Siepmann and Peppas 2011). When the release experiments of herbicides were carried out from AMPA, BZA, IDA, IMDAZ, MPA, the determined $n$ values were below 0.45 that indicated that the release could be based on the Fickian diffusion mechanism. This type of release takes place by the usual molecular diffusion of active compound due to a chemical potential gradient indicating diffusional controlled release of active ingredient (Sahoo et al. 2012). However, when TU was applied as a carrier for both 2,4-D and MCPA, a non-Fickian diffusion mechanism was observed. The deviations from Fickian behavior could be related to the changes in polymer structure in response to the sorption or desorption of penetrant molecules (Crank 1975). We assumed that the deviation from Fickian diffusion was observed because the TU's relaxation time (that was associated with structural changes) was different when compared to the other materials. It should be mentioned that the relaxation time is the time associated with large-scale motion in the structure of the polymer. Due to the sorption process, the motion of the polymer segments can occur. According to Alfrey, Gurnee and Lloyd, non-Fickian diffusion takes place when the diffusion and relaxation rates are similar (Alfrey et al. 1966).

\section{The influence of complex formation on the herbicides release from functionalized polystyrene beads}

Herbicides are able to form salts in soil and aquatic environments. The formation of salts with metal ions can be observed, especially when pesticides are applied in the areas located close to metallurgy or metal ore mining industry. On the other hand, it is well known that QuadraPure ${ }^{\mathrm{TM}}$ scavengers are able to form stable complexes with metal ions very rapidly. The polystyrene bead with the attached thiourea functional group (TU) forms stable complexes with the following ions: $\mathrm{Ag}, \mathrm{Au}, \mathrm{Cd}, \mathrm{Co}, \mathrm{Cu}$, $\mathrm{Fe}, \mathrm{Hg}, \mathrm{Ni}, \mathrm{Pb}, \mathrm{Pd}, \mathrm{Pt}, \mathrm{Rh}, \mathrm{Ru}, \mathrm{V}, \mathrm{Zn}$. The QuadraPure ${ }^{\mathrm{TM}}$ IDA with the attached imino diacetate group is able to form complexes with the following ions: $\mathrm{Al}, \mathrm{Ba}, \mathrm{Be}, \mathrm{Cd}, \mathrm{Co}$, $\mathrm{Cu}, \mathrm{Fe}, \mathrm{Ga}, \mathrm{In}, \mathrm{Mn}, \mathrm{Ni}, \mathrm{Pb}, \mathrm{Sr}, \mathrm{Zn}$. On the other hand, the polystyrene bead with the attached aminomethyl phosphonic acid group (AMPA) forms complexes with the following ions: $\mathrm{Al}, \mathrm{Co}, \mathrm{Cu}, \mathrm{Fe}, \mathrm{Ni}, \mathrm{V}$. QuadraPure ${ }^{\mathrm{TM}}$ scavengers 
with the attached benzyl amine group (BZA) are able to form complexes with the following ions: $\mathrm{Co}, \mathrm{Cu}, \mathrm{Ni}, \mathrm{Pd}$, $\mathrm{Rh}$. Other polystyrene beads functionalized with imidazolylpropyl amino group (IMDAZ) form complexes with the following ions: $\mathrm{Co}, \mathrm{Cu}, \mathrm{Fe}, \mathrm{Ni}, \mathrm{Os}, \mathrm{Pd}, \mathrm{Rh}, \mathrm{Ru}, \mathrm{Sn}, \mathrm{V}$. QuadraPure ${ }^{\mathrm{TM}}$ material with the attached mercaptophenyl
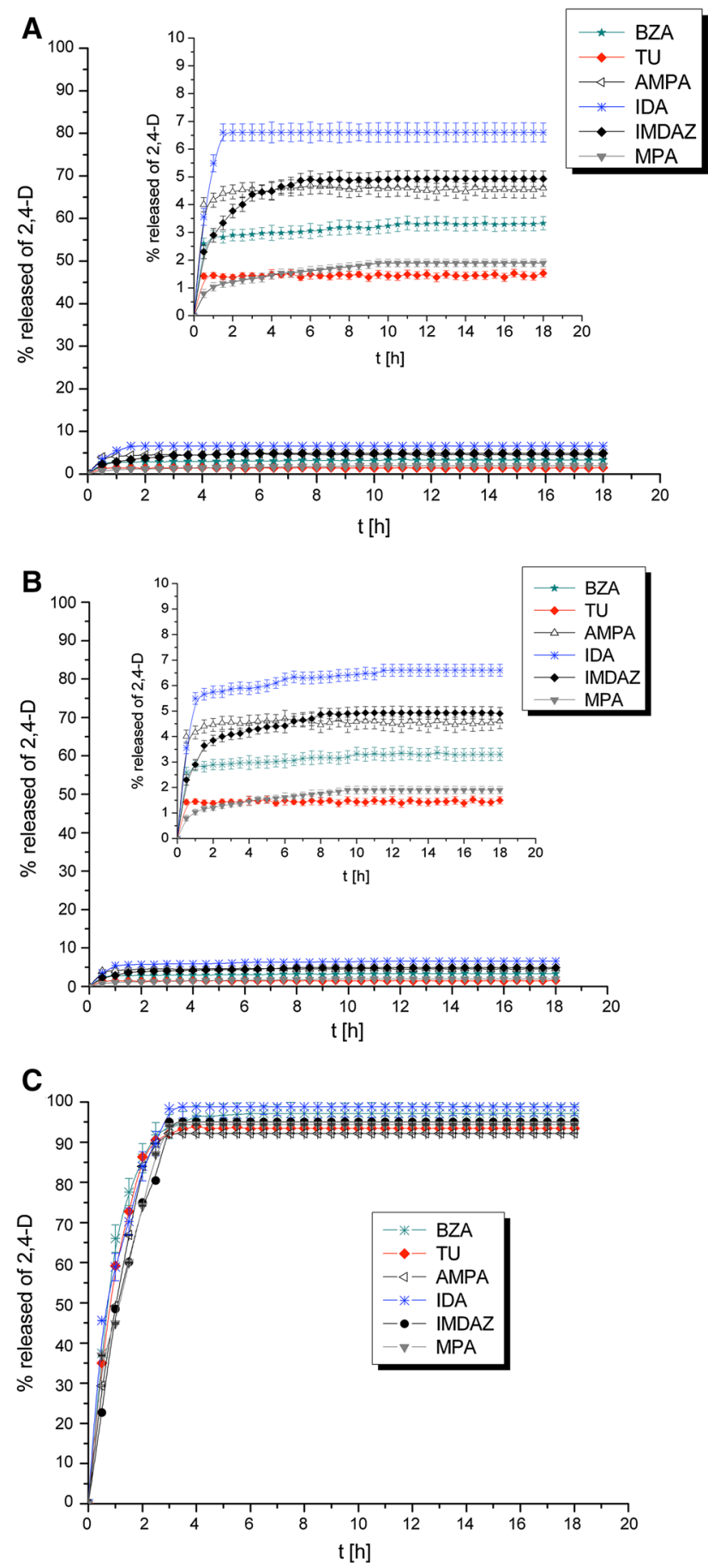

Fig. 5 Release profiles of $\mathrm{Cu}(2,4-\mathrm{D} \text { anion })_{2}(\mathbf{a}), \mathrm{Ni}(2,4-\mathrm{D} \text { anion })_{2}(\mathbf{b})$, and $\mathrm{R}_{4} \mathrm{~N}\left(2,4-\mathrm{D}\right.$ anion) (c) from various QuadraPure ${ }^{\mathrm{TM}}$ in potassium phosphate buffer at $\mathrm{pH} 6.8$
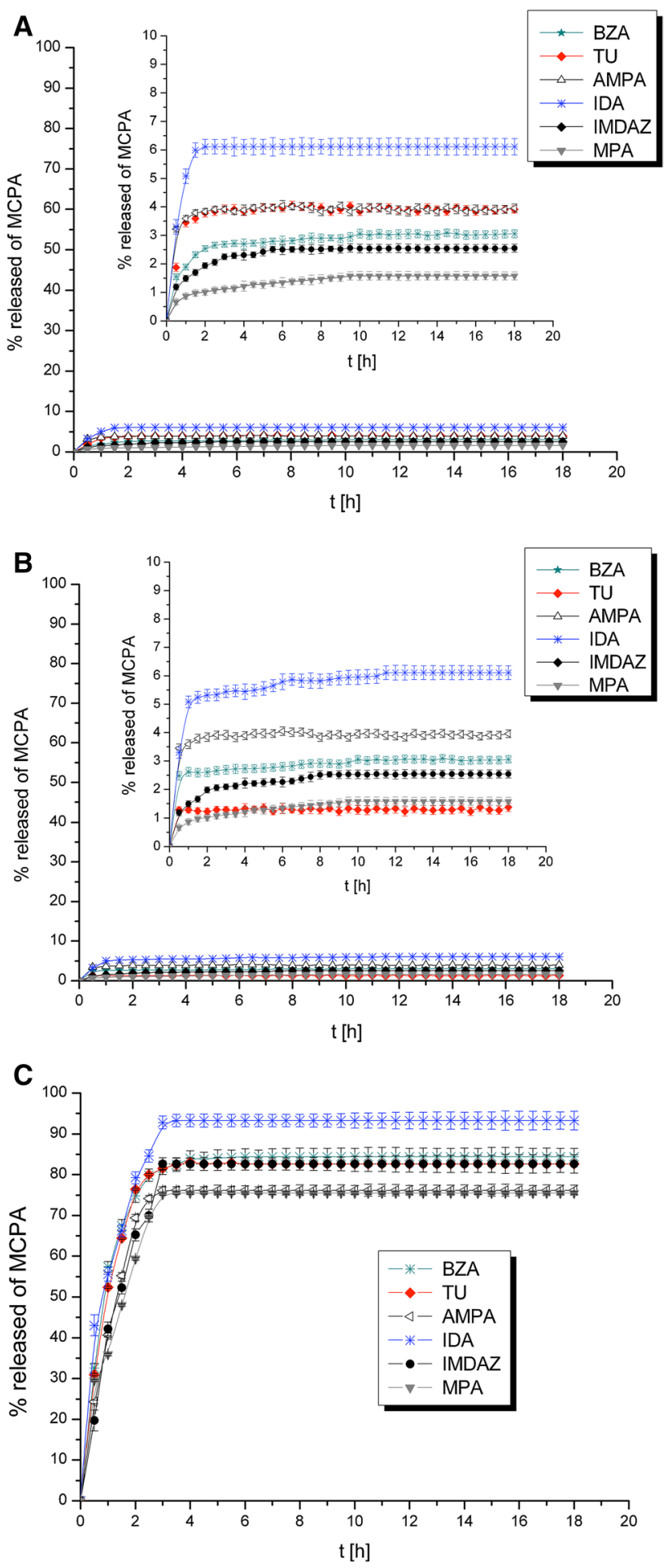

Fig. 6 Release profiles of Cu(MCPA anion) $)_{2}$ (a), Ni(MCPA anion) $)_{2}$ (b), $\mathrm{R}_{4} \mathrm{~N}$ (MCPA anion) (c) from various QuadraPure ${ }^{\mathrm{TM}}$ in potassium phosphate buffer at $\mathrm{pH} 6.8$

amino group (MPA) is able to form complexes with the following ions: $\mathrm{Au}, \mathrm{Ag}, \mathrm{Cd}, \mathrm{Cu}, \mathrm{Hg}, \mathrm{Ni}, \mathrm{Pb}, \mathrm{Pd}, \mathrm{Pt}, \mathrm{Rh}, \mathrm{Ru}, \mathrm{Sn}$ (Mikysek et al. 2008; Laska et al. 2009, Phillips et al. 2016; 
Biannic et al. 2011; Wiles and Watts 2016; Hinchcliffe et al. 2007). On the basis of these findings, one can suggest that there is a complex formation between herbicide salts and functionalized polystyrene beads. The complexation occurs between the metal ion of the herbicide salt and the QuadraPure ${ }^{\mathrm{TM}}$ material. Due to the specific functionality of QuadraPure $^{\mathrm{TM}}$, a very high affinity toward a selected metal can be designed. Therefore, the additional experiments were performed to determine the impact of complex formation on the herbicides release process. Metal ions of copper and nickel were included in these studies. The increase in the amount of these metals in the environment comes mainly from mining and smelting activities. The presence of these ions in soil and water may have influence on the efficacy of the plant protection products. Therefore, 2,4-D and MCPA in the form of copper(II), nickel(II) and tetra-nbutylammonium salts were used in the studies. The results are depicted in Figs. 5 and 6. It can be observed that the release profiles were completely different depending on the type of cation applied. Copper and nickel herbicide salts containing metal ions were strongly complexed with scavengers; therefore, only $1-7 \%$ of pesticides were released to the receptor fluid (Figs. 5a, b, 6a, b). A similar pattern was observed for both herbicide copper and nickel salts, while for 2,4-D-tetra- $n$-butylammonium and MCPA-tetra- $n$-butylammonium salts containing $\mathrm{R}_{4} \mathrm{~N}^{+}$cation the complex formation with QuadraPure ${ }^{\mathrm{TM}}$ was not detected. Within $3 \mathrm{~h}, 70-100 \%$ of herbicide was released to the receptor medium (Figs. 5c, 6c). The formation of stable complexes between QuadraPure ${ }^{\mathrm{TM}}$ and metal ions (copper or nickel) inhibited the release of pesticides. The undissociated herbicide anion was bonded to the molecular scavenger. There were no interactions between tetra- $n$-butylammonium herbicide salts and QuadraPure ${ }^{\mathrm{TM}}$ due to the presence of large cation $\mathrm{R}_{4} \mathrm{~N}$. Additionally, the herbicide salts in this case were completely dissociated. The results proved that the efficacy of herbicides was determined by the presence of metal ions and chelating ligands in the environment. Different scientific groups have already studied the complexes with herbicides and salts based on pesticides (DrzewieckaAntonik et al. 2017; Zhou et al. 2017; Cao et al. 2018; Marcinkowska et al. 2017). It has been reported that in a weak acid or neutral medium, both 2,4-D and MCPA can form complexes with bivalent metals (such as $\mathrm{Cu}, \mathrm{Ni}$ ) that are poorly water soluble (Kobylecka and Skiba 2008; Skiba et al. 2017). Therefore, we suggest that the poor solubility of complexes in water can have influence on their efficacy. It has been proved that for the areas located close to metal production plants or metal ore mines the use of herbicides in the form of ammonium salts should be recommended.

\section{Conclusion}

The influence of the structure of QuadraPure ${ }^{\mathrm{TM}}$ on the release rate of 2,4-D and MCPA was examined. The desorption of herbicides was proved to be strongly affected by the presence of specific functional groups attached to QuadraPure $^{\mathrm{TM}}$. It was suggested that the optimal hybrid systems were the mixtures able to release great amounts of herbicides for a long time. These conditions were fulfilled by IDA (imino diacetate) and TU (thiourea) for 2,4-D and by TU for MCPA. Additionally, it was detected that QuadraPure ${ }^{\mathrm{TM}}$ scavengers were able to form stable complexes with copper and nickel herbicides salts, which limits the pesticide release. The efficacy of herbicides could be determined by the presence of metal ions and chelating ligands in the environment. The application of a hybrid system permits a reduction in the dose of herbicide required. Additionally, it can ensure a higher absorption rate by plants as a result of a slow release pattern of herbicide.

Acknowledgements We would like to thank Polish Ministry of Science and Higher Education for financial support.

Open Access This article is distributed under the terms of the Creative Commons Attribution 4.0 International License (http://creativeco mmons.org/licenses/by/4.0/), which permits unrestricted use, distribution, and reproduction in any medium, provided you give appropriate credit to the original author(s) and the source, provide a link to the Creative Commons license, and indicate if changes were made.

\section{References}

Abigail EA, Chidambaram R (2016) Rice husk as a low cost nanosorbent for 2,4-dichlorophenoxyacetic acid removal from aqueous solutions. Ecol Eng 92:97-105

Alfrey T, Gurnee JR, Lloyd WG (1966) Diffusion in glassy polymers. J Polym Sci Part C 12:249-261

Aquino AJA, Tunega D, Haberhauer GF, Gerzabek MH, Lischka H (2007) Interaction of the 2,4-dichlorophenoxyacetic acid herbicide with soil organic matter moieties: a theoretical study. Eur J Soil Sci 58:889-899

Aylward LL, Hays SM (2008) Biomonitoring equivalents (BE0 dossier for 2,4-dichlopophenoxyacetic acid (2,4-D) (CAS No. 94-75-7). Regul Toxicol Pharm 51:S37-S48

Biannic B, Ghebreghiorgis T, Aponick A (2011) A comparative study of the Au-catalyzed cyclization of hydroxyl-substituted allylic alcohols and ether. Beilstein J Org 7:802-807

Boivin A, Amellal S, Schiavon M, van Genuchten MT (2005) 2,4-D sorption and degradation dynamics in three agricultural soils. Environ Pollut 138:92-99

Cao L, Zhou Z, Niu S, Cao C, Li X, Shan Y, Huang Q (2018) Positive-charge functionalized mesoporous silica nanoparticles as nanocarriers for controlled 2,4-dichlorophenyxy acetic acid sodium salt release. J Agric Food Chem 66:6594-6603 
Costa P, Lobo JMS (2001) Modeling and comparison of dissolution profiles. Eur J Pharm Sci 13:123-133

Crank J (1975) The mathematics of diffusion. Clarendon Press, Oxford

Dash S, Murthy PM, Nath L, Chowdhury P (2010) Kinetic modeling on drug release form controlled drug delivery systems. Acta Pol Pharm 67:217-223

Drzewiecka-Antonik A, Ferenc W, Wolska A, Klepka MT, Cristovao B, Szarzynski J, Rejmak P, Osypiuk D (2017) The Co(II), Ni(II) and $\mathrm{Cu}(\mathrm{II})$ complexes with herbicide 2,4-dichlorophenoxyacetic acid-synthesis and structural studies. Chem Phys Lett 667:192-198

Gold AJ, Morton TG, Sullivan WM, McClory J (1988) Leaching of 2,4-D and dicamba from home lawns. Water Air Soil Poll 37:121-129

Goscianska J, Nowak I, Olejnik A (2016) Sorptive properties of aluminium ions containing mesoporous silica towards L-histidine. Adsorption 22:571-579

Hildebrand PW, Guenther S, Goede A, Forrest L, Froemmel C, Preissner R (2008) Hydrogen-bonding and packing features of membrane protein: functional implications. Biophys J 94:1945-1953

Hinchcliffe A, Hughes C, Pears DA, Pitts MR (2007) QuadraPure cartridges for removal of trace metal from reaction mixtures in flow. Org Process Res Dev 11:477-481

Howard PH (1991) Handbook of environmental fate and exposure data for organic chemicals. Lewis Publishers, Chelsea

Iconomopoulou SM, Andreopoulou AK, Soto A, Kallitsis JK, Voyiatzis GA (2005) The effect of the molecular orientation on the release of antimicrobial substances from uniaxially drawn polymer matrixes. J Control Release 102:223-233

Kobylecka J, Skiba E (2008) The effect of phenoxyacetic herbicides on the uptake of copper, zinc and manganese by Triticum Aestivum L. Pol J Environ Stud 17:895-901

Laska U, Frost CG, Price GJ, Plucinski PK (2009) Easy-separable magnetic nanoparticle-supported Pd catalysts: kinetics, stability and catalyst re-use. J Catal 268:318-328

Lewandowski D, Olejnik A, Schroeder G (2014) Adsorption studies and release of selected dyes from functionalized mesoporous MCM-41 silica. Cent Eur J Chem 12:233-241

Liew KH, Loh PL, Juan JC, Yarmo MA, Yusop MR (2014) QuadraPure-supported palladium nanocatalysts for microwave- promoted Suzuki cross-coupling reaction under aerobic condition. Sci World J 796196:1-7

Lin T, Hu Q, Xiong X, Su X, Huang Y, Jiang Z, Zhou Q, Zhao S, Zeng W (2013) Isolation and characterization of a novel 2-methyl-4-chlorophenoxyacetic acid-degrading Enterobacter sp. strain SE08. Ecotox Environ Safety 96:198-204

Marcinkowska K, Praczyk T, Gawlak M, Niemczak M, Pernak J (2017) Efficacy of herbicidal ionic liquids and choline salt based on 2,4D. Crop Prot 98:85-93

Mikysek T, Svancara I, Vytras K, Banica FG (2008) Functionalised resin-modified carbon paste sensor for the voltammetric determination of $\mathrm{Pb}(\mathrm{II})$ within a wide concentration range. Electrochem Commun 10:242-245

Nadiminti PP, Rookes JE, Yao DD, Sayer C, Boyd BJ (2016) Nanostructured liquid crystalline particle assisted delivery of 2,4-dichlorophenoxyacetic acids to weeds, crops and model plants. Crop Prot 82:17-29

Nikbin N, Ladlow M, Ley SV (2007) Continuous flow ligand-free Heck reactions using monolithic Pd[0] nanoparticle. Org Process Res Dev 11:458-462

Olejnik A, Kapuscinska A, Schroeder G, Nowak I (2017) Physicochemical characterization of formulations containing endomorphin-2 derivatives. Amino Acids 49:1719-1731

Pernak J, Syguda A, Janiszewska D, Materina K, Praczyk T (2011) Ionic liquids with herbicidal anions. Tetrahedron 67:4838-4844

Pernak J, Syguda A, Materina K, Janus E, Kardasz P, Praczyk T (2012) 2,4-D based herbicidal ionic liquids. Tetrahedron 68:4267-4273

Pernak J, Niemczak M, Materna K, Marcinkowska K, Praczyk T (2013) Ionic liquids as herbicides and plant growth regulators. Tetrahedron 69:4665-4669

Phillips S, Holdsworth D, Kauppinen P, Namara CM (2016) Palladium impurity removal from active pharmaceutical ingredient process streams. Johns Matthey Technol Rev 60:277-286

Praczyk T, Kardasz P, Jakubiak E, Syguda A, Materna K, Pernak J (2012) Herbicidal ionic liquids with 2,4-D. Weed Sci 60:189-202

Ramteke KH, Dighe PA, Kharat AR, Patil SV (2014) Mathematical models of drug dissolution: a review. Sch Acad J Pharm 3:388-396

Richardson JM, Jones CW (2006) Poly(4-vinylpyridine) and quadrapure TU as selective poisons for soluble catalytic species in palladium-catalyzed coupling reactions-application to leaching from polymer-entrapped palladium. Adv Synth Catal 348:1207-1216

Riger PL, Peppas NA (1987) A simple equation for description of solute release II. Fickian and anomalous release from swellable devices. J Control Release 5:37-42

Sahoo S, Chakraborti CK, Behera PK (2012) Development and evaluation of gastroretentive controlled release polymeric suspenisons 
containing ciprofloxacin and carbopol polymers. J Chem Pharm Res 4:2268-2284

Salome C, Godswill O, Ikechukwu O (2013) Kinetics and mechanisms of drug release from swellable and non swellable matrices: a review. Res J Pharm Biol Chem Sci 4:97-103

Schwetlick K (1971) Kinetische Methoden zur Untersuchung von Reaktionsmechanismen. VEB Deutscher Verlag der Wissenschaften, Berlin

Siepmann J, Peppas NA (2011) Modeling of drug release from delivery systems based on hydroxypropyl methylcellulose (HPMC). Adv Drug Deliv Rev 48:139-157

Siepmann J, Siepmann F (2008) Mathematical modeling of drug delivery. Int J Pharm 364:328-343

Skiba E, Kobylecka J, Wolf WM (2017) Influence of 2,4-D and MCPA herbicides on uptake and translocation of heavy metals in wheat (Triticum aestivum L.). Environ Pollut 220:882-890

Stoytcheva M (2011) Pesticides-formulations, effects, fate. InTech, Rijeka

Trivedi NS, Kharkar RA, Mandavgane SA (2016) 2,4-Dichlorophenoxyacetic acid adsorption on adsorbent prepared from groundnut shell: effect of preparation conditions on equilibrium adsorption capacity. Arab J Chem. https://doi.org/10.1016/j.arabj c. 2016.07.022

Utschick H, Goetzschel K, Jaehing W (1989) Thermoanalytical investigations on transition metal 2,4-dichlorophenoxyacetates. J Therm Anal 35:925-932

Vencill WK (2002) Herbicide handbook. Weed science society of America, Lawrence

Wiles C, Watts P (2016) Micro reaction technology in organic synthesis. CRC Press, Boca Raton

Yang Y, Fang G, Wang X, Liu G, Wang S (2016) Imprinting of molecular recognition sites combined with $\pi$-donor-acceptor interactions using bis-aniline-crosslinked $\mathrm{Au}-\mathrm{CdSe} / \mathrm{ZnS}$ nanoparticles array on electrodes: development of electrochemiluminescence sensor for ultrasensitive and selective detection of 2-methyl-4-chlorophenoxyacetic acid. Biosens Bioelectron 77:1134-1143

Zhou T, Fang L, Wang X, Han M, Zhang S, Han R (2017) Adsorption of the herbicide 2,4-dichlorophenoxy acetic acid by Fe-crosslinked chitosan complex in batch mode. Desalin Water Treat 70:294-301 